\title{
Sobre la aceleración del tiempo social en la sociedad capitalista contemporánea ${ }^{1}$
}

\author{
About the acceleration of social time in the contemporary \\ capitalist society \\ Recibido: 23 de junio de 2014 - Revisado: 09 de diciembre de 2014 - Aceptado: 31 de marzo de 2015 \\ Carlos Eduardo Román Maldonado ${ }^{2}$
}

\section{Resumen}

El presente artículo encara el argumento sobre la aceleración del tiempo social contemporáneo cuyo origen se le atribuye a la colonización del mundo de la vida por la lógica expansiva y dominante del sistema capitalista al condicionar todas las actividades, relaciones y movimientos al trabajo, donde la productividad y la eficacia se orientan al crecimiento económico en un planeta industrial tecnificado. La metodología que se utiliza es la hermenéutica textual. A modo de cierre se plantea la propuesta de humanizar la economía capitalista para que el ser humano colonice las riquezas sociales; colonizar el sistema para que la vida social sea digna de ser vivida a plenitud.

\section{Palabras clave}

Aceleración del tiempo social, contemporaneidad, sistema y mundo de la vida, sociedad capitalista, tiempo social.

\begin{abstract}
This article faces the argument for the acceleration of contemporary social time whose origin is attributed to the colonization of the life world by the expansive and dominant logic of the capitalist system by conditioning all activities, relationships and movements to work, where productivity and effectiveness are oriented to economic growth in a technicized industrial planet. The methodology used is the textual hermeneutics. To conclude the proposal raises to humanize the capitalist economy for humans to colonize social wealth; colonizing the system so that social life is worth living to the fullest.
\end{abstract}

\section{Keywords}

Acceleration of social times, contemporaneity, life system and world, capitalist society, social time.
${ }^{1}$ Artículo resultado de una reflexión
que forma parte del proyecto de in-
vestigación "Implicaciones de la ace-
leración del tiempo social en la so-
ciedad contemporánea", que el autor
desarrolló en la maestría de Filosofía
en la Universidad Pontificia Boliva-
riana, Medellín, Colombia.
${ }^{2}$ Sociólogo de la Universidad de San
Buenaventura, Medellín, Colombia.
Magíster en Filosofia de la Universi-
dad Pontificia Bolivariana, Medellín,
Colombia. Profesor universitario, in-
tegrante de los coloquios de estudio y
discernimiento en Humanhabil (habili-
tación humana), Medellín, Colombia.
Correos electrónicos:
ceromanm@antropocultura.com,
croman18@yahoo.es

Para citar este artículo: Román, C. (2015). Sobre la aceleración del tiempo social en la sociedad capitalista contemporánea. Revista Civilizar Ciencias Sociales y Humanas, 15(28), 263-276. 


\section{Introducción}

El presente artículo se enmarca en el eje de la filosofía frente a los problemas del mundo: diálogo, análisis e interrogantes sobre la sociedad contemporánea, promovido por la Organización de las Naciones Unidas para la Educación, la Ciencia y la Cultura (Unesco, por su acrónimo en inglés) (Sané, 2011). Este eje interdisciplinario entre filosofía y ciencias sociales y humanas permite plantear preguntas sobre la sociedad actual para conocerla, entenderla y transformarla mediante la propuesta de acciones prácticas y orientadoras.

Siguiendo a Berger (2000) se considera que, "uno se presenta como comentador de la cultura de la época y como intérprete de la experiencia contemporánea" (p. 198). De este modo, pretendemos con este trabajo apropiarnos de dicha idea para comentar la cultura de la época y la experiencia contemporánea, abordando la cuestión del tiempo social como punto de partida para elaborar categorías y conceptos que coadyuven a la comprensión de nuestro mundo actual.

Al plantear el fenómeno de la aceleración del tiempo social como objeto de estudio, estamos señalando una situación particular de la sociedad capitalista contemporánea que es necesario develar para conocer, entender $\mathrm{y}$ transformar. Es un fenómeno que pasa desapercibido pero que lo sentimos en la vida cotidiana porque la condición humana conocida, con aceleración del tiempo, se está radicalmente transformando en el sentido de progreso que la modernidad le ha dado. En la medida que lo vayamos haciendo evidente se nos mostrará con todas sus implicaciones.

La aceleración del tiempo social alude al signo con el que podemos identificar el curso del mundo occidental. Signo distintivo de época, de una sociedad apresurada en sus procesos sociales como consecuencia de un modelo de producción capitalista que busca el máximo beneficio y rendimiento en menor tiempo.
La metodología que se utiliza es la hermenéutica textual, donde los textos consultados se entienden desde la perspectiva del tiempo social contemporáneo, que viene a ser la categoría de análisis e interpretación. También análisis de contenido con datos e intuiciones y teorías que se ajustan a la realidad con ejemplos demostrables de la vida cotidiana.

Un aspecto importante a destacar es que las referencias consultadas de actores sociales específicos dentro del texto no tienen por intención ofrecer una aportación analítica y caracterizada de los mismos. La exposición de motivos es breve y es solo con el firme propósito de ejemplarizar algunos comportamientos que prueban la aceleración del tiempo social en el sistema capitalista occidental, que sirven para dar una mejor argumentación teórica del problema.

Se encara la tesis que considera la aceleración del tiempo social dominante contemporáneo como producto de la colonización de los mundos de vida por la lógica productiva y expansiva del sistema capitalista, con grandes efectos en el cómo individuos y colectividades estructuran sus proyectos y planes de vida: "la aceleración parece penetrar un ámbito tras otro, no solo el mundo industrial tecnificado -el centro empíricamente comprobable de cualquier aceleración-, sino igualmente la vida cotidiana, la política, la economía y el crecimiento poblacional" (Koselleck, 2007, p. 330).

Comencemos por aclarar qué entendemos por mundo de la vida y por sistema. El mundo de la vida comprende los ámbitos de actividad y relaciones del trabajo, del esparcimiento, de los intercambios sociales que se dan día a día y que están afectados por un mundo industrial tecnificado, superinformado, también por la política, la economía y el crecimiento poblacional.

Este mundo de la vida es colonizado por el sistema, es decir, un sistema como el actual 
preocupado y acelerado por la productividad, eficacia y por el crecimiento económico que termina condicionando todas las actividades, relaciones y movimientos de lo que es el mundo de la vida. El sistema, entonces, comprende aquellos ámbitos de actividad que se enlazan con el mundo del trabajo, la industria, los desarrollos tecnológicos, la política y la economía que proporcionan unos estereotipos de conducta orientados al cálculo y a la eficiencia en la organización burocrática del mundo industrial tecnificado.

Con estos conceptos de sistema y mundo de la vida identificaremos las implicaciones de la aceleración del tiempo social en la sociedad contemporánea, en razón de "La aceleración del tiempo, entendida como incremento de la velocidad de desplazamiento de mensajes, personas y mercancías va a ser uno de los grandes factores condicionantes de la experiencia del hombre en la vida moderna" (Beriain, 2008, p. 54. La cursiva es del autor). Tanto es así que para Hartmut Rosa (2011) una característica de la modernidad "es la experiencia de un cambio en la estructura temporal de la sociedad o, más exactamente, la experiencia de aceleración de la vida, cultura y/o historia" (p. 9).

La sociología estudia el tiempo social de manera heurística haciéndose preguntas e indagando en la realidad de ese fenómeno social sentido, parecido a lo que hace el minero cuando excava en la tierra para extraer los minerales que están allí contenidos. El sociólogo con este fenómeno social "aceleración del tiempo" ahonda en la realidad para sacar fuera el rostro que estaba contenido, metáfora que sirve para reconocer la apertura a la realidad concreta.

El esfuerzo metodológico de Marx, Weber y Durkheim fue el de haber tomado como objeto de estudio la sociedad concreta, real, "lo concreto es concreto porque es la síntesis de múltiples determinaciones, por lo tanto, unidad de lo diverso" (Marx, 1975, p. 50). De esta forma, la noción de sociedad concreta es muy distinta a las sociedades imaginarias o abstractas sugeridas por Platón o San Agustín.

Beriain (2008) en su obra Aceleración y tirania del presente, habla de las estructuras temporales de la modernidad para apelar a las sociedades modernas. Nosotros preferimos decir contemporaneidad, haciendo referencia al tiempo o época en que se vive, debido a que la aceleración es un fenómeno actual del desarrollo del capitalismo con incidencia en el ethos social, o en los modos de comportamiento habituales de nuestra sociedad que modifica los ritmos de vida temporales al hacerla más rápida.

Esta circunstancia genera una experiencia distinta con connotaciones cualitativamente nuevas derivadas del movimiento en el mundo social. El inicio del capitalismo por los actores económicos en los siglos XIX y comienzos del $\mathrm{XX}$, no conoció los desarrollos posteriores ni las implicaciones socioculturales que hoy tenemos, sobre todo con la actitud hacia el consumo de la sociedad de masas (c.f. Bell, 2007).

Aunque las vamos a emplear de manera recurrente, esta no es una investigación sobre la historiografía y semántica de los conceptos modernidad o contemporaneidad, al modo de Koselleck (1993, p. 287-332), pues no es el interés delimitar ni examinar estas temporalidades cronológicamente. Nuestro propósito es caracterizar la experiencia contemporánea en relación con la aceleración del tiempo social, como expresión de un problema que se da en la época actual.

Veremos cómo el tiempo social del sistema capitalista presenta una lógica de producir más en menor tiempo, causando aceleración. Aunque también se dan situaciones que gestan procesos de desaceleración. Dialéctica inherente al tiempo social que suscita sus contradicciones debido a la complejidad social que luce Occidente, que a pesar de ser referido muchas veces como un todo cultural, encierra en sí diversidad de pensamientos y tradiciones. 
Es necesario recordar que la sociedad contemporánea es un todo diferenciado, posible de comprenderse con la idea de Alfred Schütz (1974), de realidades múltiples, donde "los seres humanos experimentan la realidad como conteniendo zonas con diferentes cualidades" (citado en Beriain, 1996, p. 260). Esto es así porque "la realidad no es una situación lineal, cuyas regularidades determinan las interacciones humanas" (Román-Maldonado, 2008, pp. 8-9).

Cuando hablamos de sistema y mundo de la vida lo hacemos para distinguir estas realidades del mundo social analíticamente. $\mathrm{La}$ observación metodológica en ningún momento implica separación, oposición o contradicción entre las categorías, pues la sociedad en general es un todo diverso compuesto por realidades multidimensionales.

La aceleración del tiempo social obedece a la fase de globalización del sistema capitalista que abarca a la sociedad occidental en general causando resonancia en todos los entornos sociales. Así como la fuerza de gravedad ejerce atracción sobre todos los cuerpos, así mismo la sociedad capitalista de Occidente hace valer su fuerza gravitatoria con intensidad relativa entre todos los actores interactuantes en el planeta. Esta lógica hace hegemónico o dominante el tiempo social al imponerse sobre mundos de vida donde existe otra temporalidad social.

\section{Tiempo social}

El tiempo social presenta dos dimensiones que se distinguen entre sí: tiempo cualitativo (significativo) y tiempo cuantitativo (cronológico), cada uno con sus atributos. Esta discriminación no implica separación, antes bien, coexisten en el seno de las sociedades como producto de la vida social, son "el conjunto de relaciones significativas -de metáforas que representan el transcurso social-" (Beriain, 2008, p. 27. La cursiva es del autor).
El tiempo social coproduce y reproduce lo sociohistórico. Nos encontramos pues con dos dimensiones temporales, en las cuales la acción social se inscribe en un tiempo concreto, donde construye, deconstruye y reconstruye la sociedad misma (c.f. Beriain, 1990). Este proceso es dialéctico no lineal, quiere decir que a veces tales dimensiones se encuentran, se articulan pero otras se contradicen. Es decir, lo social y lo histórico no son dos realidades separadas y excluyentes, sino que se vinculan debido a que lo social se va produciendo y transformando en nuevas realidades sociales por la acción de los hombres en el tiempo.

Entre una situación y unas conductas sociales se interpone la formación de sentido, un "sistema de orientación de las conductas", fruto de la capacidad de creación simbólica del individuo. Aquí es donde opera el imaginario social como núcleo de creatividad sociocultural en el que se inscriben significaciones sociales como el mito, la religión, el progreso, etc. [...]. Esto muestra que el tiempo instituido nunca puede ser reducido a su aspecto puramente identitario, de calendario y mensurable (Beriain, 1996, pp. 59-62. La cursiva es del autor).

Cuando apuntamos a la temporalidad cronológica lo hacemos con respecto al tiempo calendario, al tiempo cuantitativo, correspondiente a los segundos, minutos, horas, días, meses, años, décadas, centurias, siglos; mientras que cuando hablamos de temporalidad subjetiva lo hacemos con respecto a su contenido de significado específico, a su tiempo cualitativo, atinente a las celebraciones, conmemoraciones, remembranzas. Ambos tiempos comportan una relación de inherencia recíproca en la sociedad como tal (c.f. Beriain, 1996, pp. 59-64; Koselleck, 2001; Valencia, 2007).

Estos ritmos temporales se expresan en calendarios. Al decir de Durkheim (1992), "Las divisiones en días, semanas, meses, años, etc., corresponden a la periodicidad de los ritos, fiestas y ceremonias públicas. Un calendario 
da cuenta del ritmo de la actividad colectiva al mismo tiempo que tiene por función asegurar su regularidad" (p. 9). El calendario distribuye las actividades que una colectividad realiza periódicamente en distintas fechas durante un lapso determinado.

Las fechas indican el conjunto de relaciones significativas de lo ocurrido en un lugar que identificamos como tiempo social (significativo y cronológico), diferenciando aquellas fechas extraordinarias de las ordinarias por los sucesos o eventos ocurridos en la historia de las sociedades. Así las cosas, las sociedades históricas constituidas presentan calendarios que distinguen en sus relaciones significativas días extraordinarios de los ordinarios en la semana, donde la densidad social es distinta en cada caso. Miremos como ejemplo algunas de estas relaciones temporales de la actividad colectiva. En Colombia se reparten de la siguiente forma:

El tiempo social (significativo y cronológico) del grito de independencia, el 20 de julio de 1810, y la Batalla de Boyacá, el 7 de agosto de 1819, que rememoramos como días de fiesta nacional, cada fecha con su contenido de significado específico. Lo mismo en días de fiesta religiosa, como la Navidad, el 25 de diciembre, y el 6 de enero, día de los reyes magos. Diferenciando la alternancia periódica entre los días ordinarios de la semana de los extraordinarios de fin de semana y festivos (Beriain, 2008, p. 24). Sin embargo, esta distinción se ha ido perdiendo como consecuencia de que algunos de los actores de la economía de servicios están abriendo sus negocios los días extraordinarios, domingos y festivos. En el teletrabajo también se presenta esta situación indiferenciada de los días de la semana. Otro ejemplo es el correspondiente con el tiempo capitalista (o tiempo sistémico productivo)

[...] donde la institución explícita del tiempo identitario es un flujo mensurable, homogéneo, totalmente aritmético; y donde el tiempo imaginario es un tiempo "infinito", representado como tiempo de progreso indefinido, de crecimiento ilimitado, de acumulación, de racionalización, de conquista de la naturaleza, de aproximación cada vez mayor a un saber exacto total, de realización de un fantasma de omnipotencia (Beriain, 1996, p. 62).

Los antropólogos dicen del tiempo en las sociedades tribales (o tiempo de los mundos de vida)

Para indicar la duración del tiempo, los pueblos primitivos (véase las sociedades segmentadas) utilizan otros medios, derivados de sus quehaceres diarios, que nada tienen que ver con las computaciones del tiempo; en Madagascar la "cocción del arroz" significa con frecuencia media hora, "freír una langosta" un momento. Los nativos de Cross River dicen: "el hombre murió en menos tiempo que el maíz tarda en tostarse completamente", es decir, en menos de aproximadamente quince minutos; "el tiempo en que uno puede cocer unas verduras", es decir, una hora (Nilsson, 1920, p. 42, citado en Beriain, 2008, pp. 35-36).

El estudioso Jaén Navarro (comunicación personal, 20 de agosto de 2012) nos confiesa sobre el tiempo del kairós en el cristianismo:

El tiempo del cristianismo es vivir unidos a Cristo en el tiempo: "[...] Y he aquí que yo estoy con vosotros todos los días hasta el fin del mundo" (Mt 28, 20). Es el tiempo el momento del encuentro salvífico con Cristo. Por eso el tiempo para el cristiano no es simplemente la sucesión de las horas, los días, los meses, los años, etc., sino el kairós, es decir, el momento favorable en el cual Cristo salva, redime, instruye, provee, plenifica la vida humana. Este es el contenido de "todos los días hasta el fin del mundo". Por eso el llamado es a vivir, percibir, recibir y gozar el kairós de cada instante.

Los procesos sociales llevan sus tiempos. "En la actualidad cada cosa cambiante lleva la medida de su tiempo. [...]. Existen en el universo innumerables tiempos" (Herder, 1995, p. 68, 
citado en Beriain, 1996, p. 65). En completa correspondencia, Koselleck (1993) plantea que el tiempo "está vinculado a unidades políticas y sociales de acción, a hombres concretos que actúan y sufren, a sus instituciones y organizaciones. Todas tienen determinados modos de realización que les son inherentes, con un ritmo temporal propio" (p. 14).

Este aspecto hay que tenerlo en cuenta porque tanto el sistema como el mundo de la vida tienen sus tiempos y ritmos internos de desarrollo. Vemos pues cómo el tiempo capitalista apunta al tiempo cronológico o cuantitativo y el tiempo del mundo de la vida al tiempo significativo o cualitativo. Esta situación nos lleva a sugerir que el tiempo social del sistema y el tiempo social del mundo de la vida son temporalidades distintas, se realizan con diferentes ritmos temporales. El problema radica, como veremos, en que el tiempo del sistema impone sus lógicas productivas y expansivas sobre el tiempo del mundo de la vida, afectando la vida de las personas al acelerar el ritmo social.

Beriain (2008, p. 34) identificó al menos tres metáforas para explicar el tiempo social en algunas culturas históricas: el círculo, la flecha y el punto. El círculo es el tiempo cíclico de los griegos, el eterno retorno, "el movimiento circular que asegura la supervivencia de las cosas a través de su repetición, originando su retorno continuo [...]" (p. 41). Una vez acabados los años del ciclo del periodo, se cuentan de nuevo.

Con la flecha el autor identifica al tiempo cristiano escatológico de salvación de las almas, donde hay un principio y un fin. El alfa y la omega, el génesis y el apocalipsis. Es un tiempo lineal que va hacia adelante después de la venida de Jesucristo, en línea recta, a través de la secuencia de los días, las semanas, los meses, los años, etc.

El cristianismo nació de un fermento apocalíptico, bebió en la expectativa de un final del mundo, una expectativa que orientó las mentes de los creyentes hacia el futuro, hacia un evento concreto que pudiera completar aquel otro evento, la primera venida (Beriain, 2008, p. 47).

Con el punto reconoce el tiempo siempre presente, el aquí y el ahora, donde hay una desconexión entre las expectativas del futuro y las experiencias pasadas, haciendo del presente algo eterno, identificando el futuro con lo actual, por esto el presente hay que vivirlo con intensidad.

Todo simultáneamente y al instante, este es el mito-motor que nos mueve, cuantas más cosas hagamos al mismo tiempo y cuanto más rápido las hagamos, mejor. Todo lleva la marca del cambio permanente y acelerado, nada puede valer y ser considerado como algo seguro y permanente en el tiempo (Beriain, 2008, p. 56).

Es importante tener en cuenta estas metáforas sobre el tiempo porque vamos a ver más adelante las implicaciones que tienen en la aceleración del tiempo, sobre todo la flecha y el punto. La flecha, porque el discurso escatológico de salvación es secularizado con la idea de progreso; y el punto, es un asunto que incentiva el consumo en la sociedad capitalista en la actualidad.

Estas situaciones variables del tiempo es lo que Koselleck (2001) denomina "estratos del tiempo". Como ya advertimos, el tiempo social no es uno, ni único, ni singular. Mucho por el contrario. Hay diferentes movimientos temporales. "Remitir a la historia humana, política y social, y a la estructura histórica permite separar analíticamente diferentes niveles temporales en los que se mueven las personas, se desarrollan los acontecimientos o se averiguan sus presupuestos de larga duración" (p. 35).

Más adelante el autor agrega: "Y es que los tiempos históricos constan de varios estratos 
que remiten unos a otros y sin que se puedan separar del conjunto" (Koselleck, 2001, p. 36). "La ganancia de una teoría de los estratos del tiempo consiste por tanto en poder medir distintas velocidades, aceleraciones o demoras, y hacer así visibles distintos modos de cambio que ponen de manifiesto una gran complejidad temporal" (p. 38). Es lo que queremos hacer notar con el cambio temporal de la sociedad occidental contemporánea.

\section{Aceleración del tiempo social}

En palabras de Jacob Burckhardt (1949): "el proceso mundial conlleva una rapidez espantosa; los desarrollos que precisaban siglos se muestran en meses y semanas, como fantasmas volantes que pasan por delante, listos para pasar a la existencia" (citado en Beriain, 1996, p. 215).

En este sentido, la dinámica del tiempo social parece ser la idea de rápido, más rápido; es decir, la aceleración, el incremento de velocidad en la unidad de tiempo de las acciones sociales. Es pues algo exponencial. Más interacción en un mismo periodo de tiempo, que acrecienta la actividad humana. Aumentamos la frecuencia de lo que ocurre en un momento, se mantienen las mismas coordenadas de tiempo, un segundo, una hora; lo que ocurre es que la frecuencia en esa unidad de tiempo se amplía o multiplica, intensificándose el uso de ese tiempo. Al respecto, Karl Marx (1974) al referirse a la intensificación del trabajo fabril en Inglaterra, asevera:

Es evidente que, al progresar la maquinaria, $\mathrm{y}$ con ella la experiencia de una clase especial de obreros mecánicos, aumenta, por impulso natural, la velocidad, y, por lo tanto, la intensidad del trabajo. [La intensidad del trabajo] consiste en hacer que el obrero, intensificando la fuerza productiva del trabajo, pueda producir más con el mismo desgaste de trabajo y en el mismo tiempo (p. 337. La cursiva es del autor).

Aquí vemos pues un rasgo característico que produce la aceleración, su consideración industrial, que luego miraremos con la idea de progreso, como un indicador empírico, porque ahora queremos seguir con la situación que planteó Marx (1974) sobre el inicio del capitalismo, que sucede hoy día, pero haciéndose extensiva a otros ámbitos de la acción social. Aquí es donde decimos que procesos de racionalidad administrativaeconómica penetran las conductas humanas, al monetizar y burocratizar la interacción social. Esto es, la comunicación intersubjetiva mediada por el lenguaje y los símbolos, es minimizada por estructuras normativas, que reducen la interacción al rol funcional.

Entendemos entonces, cómo las estructuras funcionales del sistema incrementan el flujo de actividades en el mismo periodo de tiempo. Identificando esta acción como racional con arreglo a fines, como diría Max Weber (1997), por el afán de lucro y el enriquecimiento desmedido de una economía capitalista irracional, que produce más y nuevas necesidades de las que la sociedad como tal pueda consumir. Esto es así porque aumentan los constreñimientos institucionales al configurar nuevas condiciones sociales que nos convierten

[...] en dependientes del mercado de trabajo y con ello también en dependientes de una formación escolar, en dependientes del consumo, en dependientes de las regulaciones y providencias típicas del Estado social, de las planificaciones del tráfico, de las ofertas de consumo, de las posibilidades y modas, de la atención médica, psicológica y pedagógica (Beck, 1986, p. 219, citado en Beriain, 2011, p. 6),

Similar a lo que expresaron Horkheimer y Adorno en su clásica obra Dialéctica de la ilustración (1998) sobre la industria cultural que dirige el gusto al consumo de masas.

La aceleración del tiempo social es producto de la sociedad capitalista en cuanto tal, que produce y reproduce lo propio, lo suyo. Sus 
formas de ser social. La interacción social va produciendo y reproduciendo nuevos hechos con sus morfologías, en los que se manifiesta lo social instituyendo significados y sentidos en el representar decir/hacer sociales "[...] un nuevo contenido social a expresar" (Beriain, 1990, p. 20) que se hace pegamento en lo sociohistórico.

Vale la pena recordar lo que dice LéviStrauss (1965) de la sociología de Gurvitch: "la vida social habría que ser considerada como el brotar continuo de una multitud de formas sociales, siempre nuevas" (p.26). Así pues, el tiempo social deviene condición de posibilidad, en tanto la aceleración crea situaciones densas en la vida colectiva. "Una sociedad se produce $\mathrm{y}$ reproduce en la medida que va generando con sus acciones en el mundo nuevos significados. Esta es la dinámica de la vida social" (RománMaldonado, 2003) de la sociedad instituyente sobre la sociedad instituida.

\section{El tiempo social en la contemporanei- dad}

Lo anterior se entiende en la época contemporánea por los procesos originados de la racionalización sociocultural y de la diferenciación funcional de las sociedades occidentales, donde hay un desacoplamiento entre sistema y mundo de la vida. La racionalidad administrativa-económica del sistema se hace explícita cuando en los núcleos vitales del mundo de la vida, el hogar, por ejemplo, hacemos labores de la división social del trabajo, es decir, nos llevamos el trabajo para la casa. Inclusive se incrementa esta actividad según la densidad laboral los fines de semana, días no laborales, reduciendo el tiempo libre a nuestra disposición de los días extraordinarios cuya densidad es distinta (c.f. Delfino, 2011, p. 98). Multiplicando o incrementando las actividades de la vida social en un periodo de tiempo, entonces por eso decimos que el tiempo pasa volando.

La aceleración del tiempo social se siente en este tipo de situaciones funcionales, donde el tiempo cronológico pasa a una velocidad que no permite asimilación del tiempo significativo y los días extraordinarios son equiparables con los ordinarios, simplificando gradualmente la alternancia periódica entre los días ordinarios de los extraordinarios. Esta circunstancia hace que el mundo de la vida quede reducido a su mínima expresión simbólica.

El progreso hace que se acrecienten sin fin nuevas y más necesidades, este aumento produce aceleración, en cuanto la acción social es coordinada y regulada funcionalmente hacia el consumo de las necesidades. Transitamos así de una sociedad industrial, manufacturera, productora de bienes, a una sociedad de servicios, que se ofrecen a los consumidores, por el afán de posesión material de las personas, lo cual podemos denominar hedonismo hacia el consumo.

El consumir nos hace sentir bien, felices, pero ese placer hacia el consumo genera el incremento de la producción en los bienes y servicios de la economía causando aceleración. Es de recodar que la economía en una sociedad capitalista se orienta al crecimiento de las ganancias y utilidades, por tanto, "la lógica del capitalismo conecta el crecimiento con la aceleración, necesitado como está de incrementar la producción (crecimiento) así como la productividad (definida en términos temporales como el rendimiento por unidad de tiempo)" (Beriain, 2008, p. 151).

Las personas consumen "por la creciente disponibilidad de las conciencias individuales a la colonización por la industria de producción de sentimientos de carencia, por los medios de producción y difusión industriales de contenidos de conciencia" (Capella, 1993, p. 30. La cursiva es del autor). Estos sentimientos de carencia están arraigados en todos los estratos de la vida social, acentuándose aún más en personas con baja autoestima que suplen la falta con el consumo. La industria saca provecho de la coyuntura al estimular el consumo con 
sus agencias multilaterales de información y divulgación, mediante el imaginario colectivo de significaciones sociales que idealizan estereotipos funcionales. Irónicamente diríamos hoy día con Mandeville (1982) que "los vicios privados contribuyen al beneficio público".

La expresión "el tiempo es oro" hace referencia a la aceleración del tiempo social. El tiempo es oro en tanto producto por unidad de tiempo, esfuerzo aplicado al trabajo. El tiempo hay que aprovecharlo al máximo porque significa dinero, entonces hay que trabajar para conseguirlo, incrementado en consecuencia la productividad. Es la mentalidad, por ejemplo, de las prostitutas o de los taxistas, en la que el tiempo es oro, a más clientes y carreras por unidad de tiempo, más ingresos, o ya, en la modalidad tan extendida actualmente de contrato laboral, por obra o producto del mundo del trabajo; por supuesto nada comparable a los movimientos bursátiles del capital financiero, la rapidez de las comunicaciones usando la virtualidad, donde miles de millones de dólares se mueven en tiempo récord en transacciones. Aquí aplica otra noción del tiempo, no se trata de productividad, sino de rentabilidad: el tiempo como oportunidad.

En el deporte también se observa que "el tiempo es oro", pues los patrocinadores invierten millones, una milésima de segundo en competencia, cifra minúscula en tiempo altera el resultado. La prueba "reina" del atletismo de los cien metros o las carreras de velocidad de la natación estilo libre de 50 metros y 100 metros o las carreras de autos de Fórmula Uno son demostración de ello.

Para Beriain (2008, p. 144) "el tiempo es oro" es una expresión que pudo suministrarle a Weber el prototipo de conducta racional/ capitalista que describió en La ética protestante y el espíritu del capitalismo (2004). En efecto, "Esta nueva dimensión del tiempo en el capitalismo es puesta de manifiesto por Max Weber cuando la sitúa en medio de la conexión entre dinero y disciplina como un elemento central del espíritu capitalista" (Beriain, 2008, p. 144).

El ritmo de la vida social crece cada vez más, hacemos las cosas cada vez más rápido, dormimos menos, comemos con prisa, los encuentros con los pares de amigos o con la familia cada vez son menos. El hecho es que realizamos más actividades que nuestros antecesores aumentando la densidad social en un periodo de tiempo. Optimizamos los recursos por nuestra mentalidad racional que instrumentaliza la naturaleza y las relaciones sociales. Los desplazamientos de un lugar a otro se hacen cada vez con más velocidad, las distancias se acortan.

Vivimos el presente como el aquí y el ahora, ya no soñamos ni pensamos en el futuro, ni hacemos planes a largo plazo (c.f. Beriain, 2008, pp. 35-69), tendencia capitalista que reduce el ámbito de pensarse a largo plazo por la lógica de acumulación de capital y productividad laboral. Por ello las expectativas de futuro se ven aminoradas o limitadas y el pasado no lo recordamos, dejando de lado las experiencias vividas de las generaciones precedentes.

Hoy día ya no imaginamos permanecer treinta años laborando en una empresa, contrario sucedía antes o un poco después de la Segunda Guerra Mundial, cuando la tendencia predominante era que una vez se firmaba el contrato, ya se sabía la fecha precisa de jubilación treinta años después. Conectamos este hecho con la aceleración en tanto colonización de las conciencias " $[. .$.$] por los medios industriales de$ incitación al consumo [más] que de percepción de la dificultad del futuro" (Capella, 1993, p. 28 ), es decir, se motiva a vivir el presente pero consumiendo, conditio sine qua non. La vida se reduce entonces al presente, al vivir el día a día muchas veces sin contenido ni significado, con un vacío existencial.

Esta situación del presente como el aquí y el ahora, es vista por Lubbe (2003, p. 399, citado 
en Beriain, 2008, p. 55) como una "contracción de la conciencia del presente", donde la carga se aligera por las omisiones del pasado y del futuro. Por esta razón, nosotros interpretamos que para Koselleck (1993, pp. 333-357) la conciencia moderna del tiempo se caracteriza por la creciente diferencia entre el espacio de experiencia y el horizonte de expectativas.

Entre el pasado, el presente y el futuro hay una multiplicación de circulación de información de los medios de comunicación, pero se disminuye el tiempo de asimilación. Entonces, en esa dinámica cada vez se va creando representativamente que lo que ocurrió ayer forma parte de un pasado lejano. Se puede inferir una connotación que socialmente se tiene sobre la información y su rápida obsolescencia.

En la llamada sociedad del conocimiento pasa algo similar con la multiplicación de circulación de información. La sociedad del conocimiento no es tan solo la producción de información, sino también la asimilación de conocimiento y su apropiación social que con la rapidez de circulación no se da (c.f. Pardo, 2008).

Dice Zuleta (1986, p. 47), comentando a Platón, que este "llama esclavos a abogados, reyes y gentes así, que carecen de tiempo, es decir de libertad para pensar", destacando la relación del tiempo con el conocimiento, con el desarrollo del saber que había en Grecia en aquella época. En la actualidad somos esclavos..., porque carecemos de tiempo para pensar. Al profesional se le vincula para hacer, no para pensar, porque no hay tiempo y además debe tener capacidad para trabajar bajo presión.

El ciclo de producción determina unos tiempos y una cualidad del mismo para las acciones humanas, que lleva prácticamente a convertir al ser humano, ya no únicamente en labores que antes se llamaban manuales, sino las nominadas como intelectuales, en un apéndice del sistema productivo, promoviendo tan solo el hacer o lo denominado como una participación técnica en el proceso, sin que se permita o habilite las posibilidades de pensar, entendidas en el sentido que le da Horkheimer (2002) a la razón dialéctica o crítica en oposición a la razón instrumental, o la analizada por Heidegger (2005) en ¿Qué significa pensar? En definitiva, ya por directrices o por agotamiento físico promovido en un hacer multiplicado, se prohíbe pensar al interior del proceso. Hay que hacerlo todo ya, "para mañana es tarde".

El ciclo de producción de la economía capitalista de la sociedad contemporánea está acelerado en sus procesos sociales. Es un rasgo distintivo de época que afecta al mundo de la vida, al apresurar el ritmo de la vida social. Dicho ciclo (producción, distribución y consumo) gira alrededor de la mercancía y se acelera al intensificarse la actividad laboral porque se reduce la jornada de trabajo, limitándose también la edad productiva del individuo. A pesar de que hay reducción de la jornada laboral hay que trabajar más, acentuándose el ciclo productivo. Entonces en un periodo de tiempo más corto hay más producción, más distribución y más consumo, al desgastarse la mercancía y volverse obsoleta más rápidamente. Esto genera cambios en la connotación cronológica de los sujetos con respecto a la vinculación de la producción.

Queremos relacionar el tiempo de vida útil de la persona con respecto al tiempo del sistema. Esta situación trae como consecuencia el desgaste de la fuerza de trabajo en menor tiempo, aunque el individuo tenga una edad menor. A los cuarenta años ya se está viejo para laborar, según se dice de modo peyorativo excluyendo al sujeto del mundo laboral. Tal situación es contradictoria frente a la esperanza de vida, que ha aumentado gracias a los avances de la medicina en la investigación científica y a los desarrollos tecnológicos en esta materia.

A este respecto, la Organización Mundial de la Salud (2008) asevera que "las tendencias 
mundiales correspondientes a la esperanza de vida muestran un aumento global de casi ocho años entre 1950 y 1978, y siete años más desde entonces" (p. 4), es decir, desde estos años hasta hoy hay una ampliación en la esperanza de vida de 15 años. Particularmente en Colombia,

[...] este indicador ha venido presentando un incremento a través del tiempo, siendo mayor la ganancia para las mujeres que para los hombres. En el periodo 1985 a 2005 la esperanza de vida al nacer aumentó 4,3 años para los hombres y 4,8 para las mujeres [...]. Entre 2005 y 2020 se estima que este indicador se incrementará de 72,6 a 76,2 años para ambos sexos [...] (Departamento Administrativo Nacional de Estadística- DANE, 2007, p. 4).

Vemos entonces cómo el sistema margina al individuo del mundo laboral porque la vida útil disminuye, entonces ¿vivir más para qué?, es lo que se podría preguntar. En el pasado, con el desarrollo industrial, las personas se vinculaban al trabajo con mayor celeridad respecto a la edad y las desvinculaban más tarde, ahora la tendencia es vincularlas más tarde y desvincularlas más temprano.

En la formación social capitalista contemporánea el mundo de la vida es colonizado por el sistema que termina condicionando todas las actividades, relaciones y movimientos. Es como si viviéramos solo para el trabajo con su estereotipo funcional, donde la productividad y la eficacia se dirigen al crecimiento económico en un mundo industrial tecnificado que sigue el ideal de progreso. Entonces la fórmula más trabajo más productividad más consumo más progreso hace que la economía capitalista sea el motor por antonomasia de la aceleración del tiempo social.

La aceleración del tiempo social es connatural al ethos social o a los modos habituales de comportamiento, a la evolución de las sociedades occidentales, a los ritmos de la vida diaria. Es el atributo que tiene la sociedad de producir y reproducir lo suyo, con lo que las relaciones sociales son un producto social por el hecho de generar nexos con los demás, formas de ser social que van instituyendo significados y sentidos en el representar decir/hacer sociales. Pero la aceleración tiene su contraparte, la desaceleración, el freno.

Buscar el equilibrio de estas dinámicas sociales es primordial para asegurar los procesos de integración social. El freno está en los procesos sociales que originaron la aceleración, como factor condicionante de la experiencia humana. Recordando con optimismo el adagio del poeta Hölderlin (1995), para quien: "cercano está el Dios y difícil es captarlo. Pero donde hay peligro crece lo que nos salva" (p. 395 citado en Beriain, 2000, p. 233-234).

\section{Conclusiones}

Es cierto que la economía capitalista tiene como freno o proceso de desaceleración a la disminución de la actividad económica que se caracteriza en general por el desempleo masivo, el decreciente uso de recursos y el bajo nivel de inversiones; sin embargo, no son suficientes para generar procesos de freno de largo aliento que sean correlativos con la aceleración. Son temporalidades de baja aceleración. Son longitudinales, una vez sorteada la época de crisis se implementan mecanismos sociales para recuperar el ritmo y crecer exponencialmente. Se crean empleos y se incentiva la inversión para el consumo en masa.

Por supuesto, también están como factores que desaceleran las sociedades rurales alejadas del ámbito urbano, sectas religiosas como los Amish, movimientos sociales antimodernistas y luditas; que van configurando un umbral de pensamiento y acción, un representar decir/hacer social que se hace pegamento en lo sociohistórico. No obstante, son actitudes particulares que no calan con la suficiente trascendencia o profundidad en la sociedad en general en cuanto tal. Solo tienen impacto en los círculos de interacción que forman la vida cotidiana de las personas. 
Estas situaciones de desaceleración o freno no se entienden como si la economía capitalista las propiciara de manera consciente o planificada para buscar equilibrios y suscitar en consecuencia procesos de integración social. La verdad del asunto es que la economía capitalista no se detiene porque el capital, como apunta Zamora (2011) siguiendo a Marx, "no tiene ningún límite interno, no existe un punto de equilibrio y descanso" (p. 4). Pretende la acumulación de capital y la creación de plusvalía a como dé lugar: "cuanto más se gana, más crece el hambre de ganancia" (Marx, 1974, p. 334).

Al tomar conciencia de este hecho se podría poner un orden, para respetar ciertos tiempos y ciertos espacios, mantener el tiempo del sistema y el tiempo del mundo de la vida en sus respectivos fueros o límites, como por ejemplo respetar los horarios de las jornadas laborales y que las asignaciones o tareas sean correlativas con los tiempos de dedicación para no invertir más de lo estipulado. En su justo equilibrio.

En otras palabras, cómo humanizar la economía capitalista para que el ser humano colonice las riquezas sociales, cómo colonizar el sistema para que la vida social sea digna de ser vivida a plenitud.

\section{Referencias}

Bell, D. (2007). Epílogo de 1996 a las contradicciones culturales del capitalismo. En J. Beriain \& M. Aguiluz (Eds.), Las contradicciones culturales de la modernidad. (pp. 43-113). Barcelona: Anthropos.

Berger, B. M. (2000). Sociology and the Intellectuals: An Analysis of a Stereotype. En Bourdieu, P., Chamboredon, J. C., \& Passeron, J. C. El oficio de sociólogo: presupuestos epistemológicos. (pp. 198-201). México: Siglo Veintiuno.

Beriain, J. (1990). Representaciones colectivas y proyecto de modernidad. Barcelona: Anthropos.
Beriain, J. (1996). La integración en las sociedades modernas. Barcelona: Anthropos.

Beriain, J. (2000). La lucha de los dioses en la modernidad. Del monoteísmo religioso al politeísmo arquetipal. Barcelona: Anthropos.

Beriain, J. (2008). Aceleración y tiranía del presente. La metamorfosis en las estructuras temporales de la modernidad. Barcelona: Anthropos.

Beriain, J. (2011). El sujeto transgresor (y transgredido). Modernidad, religión, utopía y terror. Barcelona: Anthropos.

Capella, J. R. (Ed.). (1993). El tiempo del progreso. En Los ciudadanos siervos, (pp. 1332). Madrid: Trotta.

Delfino, A. (2011). Las transformaciones en el mundo del trabajo desde la óptica temporal. Un tiempo con nuevos tiempos. Revista Colombiana de Sociología. 34(1), 85-101.

Departamento Administrativo Nacional de Estadística -[DANE]. (2007). Proyecciones de población 2005-2020. Bogotá: Departamento Nacional de Estadística.

Durkheim, E. (1992). Las formas elementales de la vida religiosa. El sistema totémico en Australia. Madrid: Akal.

Heidegger, M. (2005). ¿Qué significa pensar? Madrid: Trotta.

Horkheimer, M. (2002). Critica de la razón instrumental. Madrid: Trotta.

Horkheimer, M., \& Adorno, T. W. (1998). Dialéctica de la ilustración. Madrid: Trotta.

Koselleck, R. (1993). Futuro pasado. Para una semántica de los tiempos históricos. Barcelona: Paidós. 
Koselleck, R. (2001). Los estratos del tiempo: estudios sobre la historia. Barcelona: Paidós.

Koselleck, R. (2007). ¿Existe una aceleración de la historia? En Beriain J., \&. Aguiluz, M. (Eds), Las contradicciones culturales de la modernidad (pp. 319-345). Barcelona: Anthropos.

Lévi-Strauss, C. (1965). La sociología francesa. En Gurvitch, G. \& Moore, W. E. Sociología del siglo $X X$ (Tomo 2, 2da ed.). Barcelona: El Ateneo.

Mandeville, B. (1982). La fabula de las abejas. México: Fondo de Cultura Económica.

Marx, C. (1974). El capital. Critica de la economía política (Vol. I. Sexta reimpresión de la segunda edición en español de 1959). México: Fondo de Cultura Económica.

Marx, C. (1975). Introducción general a la crítica de la economía política-1857 (2da ed.). Medellín: Oveja Negra.

Organización Mundial de la Salud. (2008). Informe sobre la salud en el mundo 2008: La atención primaria de salud, más necesaria que nunca. Ginebra: Autor.

Pardo, J. L. (2008). El conocimiento líquido. Sobre la reforma de las universidades públicas. Revista Claves de Razón Práctica. (186), 4-11.

Román -Maldonado, C. E. (2003). Estructuración Social: de centralidad metafísico religiosa a diferenciación sistémica en Colombia. Revista Virtual Universidad Católica del Norte, 10. Recuperado de http://revistavirtual.ucn.edu.co/ index.php/RevistaUCN/article/view/310/587

Román-Maldonado, C. E. (2008). Comentario al texto Las nuevas ciencias y las humanidades. De la academia a la política.
Revista Virtual Universidad Católica del Norte, 24, 1-19. Recuperado de http://revistavirtual. ucn.edu.co/index.php/RevistaUCN/article/ view/140/268

Rosa, H. (2011). Aceleración social: consecuencias éticas y políticas de una sociedad de alta velocidad desincronizada. Revista Persona y Sociedad, 25(1), 9-49.

Sané, P. [Prefacio] (2011). La filosofía una escuela de la libertad. Enseñanza de la filosofia y aprendizaje del filosofar: la situación actual y las perspectivas para el futuro. México: UNESCO.

Valencia, G. (2007). Entre cronos y kairós. Las formas del tiempo sociohistórico. Barcelona: Anthropos.

Weber, M. (1997). Economía y Sociedad (Primera reimpresión de la segunda edición en español de la cuarta edición en alemán). Bogotá: Fondo de Cultura Económica.

Weber, M. (2004). La ética protestante y el espíritu del capitalismo (Primera reimpresión de la primera edición del 2003). México: Fondo de Cultura Económica.

Zamora, J. A. (Febrero, 2011). Aceleración: las estructuras temporales de la modernidad. En: Filosofía después del holocausto, Vigencia de sus lógicas perversas. Trabajo presentado en ponencia del Instituto de Filosofía del Centro de Ciencias Humanas y Sociales -[CSIC], Madrid-España. Recuperado de http://www.proyectos.cchs.csic.es/ $\mathrm{fdh} /$ sites/default/files/JAZamora $\% 202011 \% 20$ Aceleraci $\%$ C3\%B3n.pdf

Zuleta, E. (1986). Arte y filosofia. Medellín: Percepción. 
